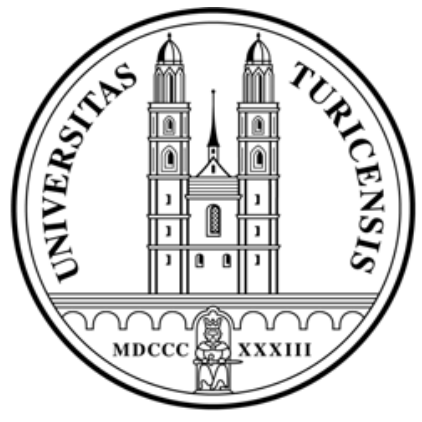

Institute for Empirical Research in Economics

University of Zurich

Working Paper Series

ISSN 1424-0459

Working Paper No. 441

\title{
Liquidity, Innovation and Growth
}

Aleksander Berentsen, Mariana Rojas Breu and Shouyong Shi

Revised version, October 2012 


\title{
Liquidity, Innovation and Growth
}

\author{
Aleksander Berentsen \\ University of Basel and FRB of St Louis \\ Mariana Rojas Breu \\ Université Paris Dauphine \\ Shouyong Shi \\ University of Toronto and CUFE (CEMA)
}

October 2012

\begin{abstract}
Many countries simultaneously suffer from high inflation, low growth and poorly developed financial sectors. In this paper, we integrate a microfounded model of money and finance into a model of endogenous growth to examine the effects of inflation on welfare, growth and the size of the financial sector. A novel feature is that the innovation sector is decentralized. Financial intermediaries arise endogenously to provide liquidity to this sector. Consistent with the data but in contrast to previous work, reducing inflation generates large growth gains. These large gains cannot be easily reproduced by imposing a cash-in-advance constraint in the innovation sector.
\end{abstract}

Keywords: Inflation; Growth; Search; Innovation; Credit. JEL Classification: E5, O42

\footnotetext{
1 Berentsen (aleksander.berentsen@unibas.ch): Department of Economics, University of Basel, Switzerland. Rojas Breu (mariana.rojas-breu@dauphine.fr): Department of Economics, Université Paris Dauphine, France. Shi (shouyong@chass.utoronto.ca): Department of Economics, University of Toronto, 150 St. George Street, Toronto, Ontario, Canada, M5S 3G7. Earlier versions of this paper (under different titles) were presented at the Society for Economic Dynamics meeting (July 2008), Federal Reserve Bank of Chicago (August 2008), Federal Reserve Bank of Philadelphia (February 2009), LACEA Conference (October 2009) and CEAFE Conference (June 2010). Berentsen gratefully acknowledges support by the Bank for International Settlements (the usual disclaimer applies). Rojas Breu acknowledges the financial support from Région Ile de France. Shi gratefully acknowledges the financial support from the Bank of Canada Fellowship, the Canada Research Chair, and the Social Sciences and Humanities Research Council of Canada. The opinion expressed here does not represent the view of the Bank of Canada or the Federal Reserve System.
} 


\section{Introduction}

Many countries simultaneously suffer from high rates of inflation, low growth rates of per capita income and poorly developed financial sectors. For example, during the period from 1960 to 1995, Bolivia had an average annual inflation rate of 50\%, a low growth rate of per capita income of $0.36 \%$, and a share of the financial sector in GDP that was about one fifth of the share in the United States. In this paper, we integrate a microfounded model of money and finance into a model of endogenous growth, and we calibrate the model to analyze how inflation quantitatively affects welfare, the growth rate of per capita income, and the size of the financial sector.

The empirical literature has documented that inflation has robust and negative effects on financial development and growth (e.g., Boyd et al., 2001, and King and Levine, 1993a,b). These effects are sizable, even after controlling for country-specific factors such as the level of a country's development, political factors, trade and price distortions, and fiscal policy. For example, the regression coefficients in Boyd et al. suggest that an increase in inflation by the median value in the sample (9\%) can reduce financial intermediation by $26 \%$ in low-inflation countries. Table 1 displays the empirical relationship between inflation, real per capita growth, and three commonly used measures of financial development. ${ }^{1}$ One measure is bank credit, defined as claims on the private sector by deposit money banks as a share of GDP. The second measure is liquid liabilities, defined as currency plus demand and interest-bearing liabilities of banks and nonbank financial intermediaries, as a share of GDP. The third measure is the net interest margin, defined as the ratio of interest income earned minus interest income paid to total assets. While a high level of bank credit or liquid liabilities indicates a high level of development and efficiency of the financial sector, a high net interest margin indicates low development and efficiency. ${ }^{2}$ Table 1 shows that countries with higher growth in real GDP per capita tend to have both larger financial sectors and lower rates of inflation.

\footnotetext{
${ }^{1}$ To construct Table 1, we have used the cross-country data of Levine et al. (2000). The data range is 1960-1995. There are 63 countries for which all data were available. We then eliminated all countries that experienced a hyperinflation during this period. The remaining countries are sorted into inflation tertiles (see the supplementary material for the countries and their allocation into the three inflation baskets). For each country type, we then calculated the average inflation rate, the average real per capita growth rate, the average of bank credit, the average of liquid liabilities, and the average of the net interest rate margin.

${ }^{2}$ Bank credit and liquid liabilities have been used in many empirical studies as indicators of financial development (e.g., Levine et al., 2000). In panel data analysis, the most common empirical measure of bank spreads is the net interest margin (Brock and Rojas-Suarez, 2000). To calculate it, we use the data in Beck et al. (2001).
} 
Table 1 (Data): Inflation, growth and financial development

\begin{tabular}{|c||c||c||c||c||c||}
\hline & inflation & growth & bank credit $^{a}$ & liquid liabilities & \\
\hline low & 5.40 & 3.12 & 0.50 & 0.67 & 0.031 \\
\hline mid & 8.78 & 1.75 & 0.28 & 0.43 & 0.034 \\
\hline high & 16.87 & 1.65 & 0.21 & 0.34 & 0.053 \\
\hline
\end{tabular}
$\begin{aligned} & { }^{a} \text { Defined as claims on private sector by deposit money banks, as share of GDP. } \\
& \text { demand }{ }^{b} \text { Defined as currency plus }\end{aligned}$
interest-bearing liabilities of banks and nonbank financial intermediaries, as share of GDP.
${ }^{c}$ Defined as interest income earned minus interest income paid divided by total assets.

To study the effects of inflation on growth, welfare and financial sector size, we extend the search model developed by Shi (1997) to allow for financial intermediation and a balanced growth path. The representative household in the model consists of a continuum of members who are allocated to four activities: producing consumption goods, innovating, working in the financial sector, and leisure. The innovation sector uses labor (innovation time) as the input in the production of "knowledge capital", which in turn increases labor productivity in the final-goods sector. As in a standard model of endogenous growth, nondiminishing marginal productivity of knowledge capital is the source of long-run growth.

As a key departure from the literature, we model the innovation sector as a decentralized market where innovators are matched randomly and bilaterally. ${ }^{3}$ There is no double coincidence of wants between any two innovators and no record-keeping of innovators' transactions, and so a medium of exchange is needed for trading innovation time. Moreover, in any given period, trading shocks generate heterogeneous demand for liquid funds among innovators. Financial intermediaries emerge endogenously to reallocate liquid funds among innovators. As in Berentsen et al. (2007), these intermediaries behave like banks, since they take deposits and make loans.

To quantify the effects of inflation, we calibrate our model to the average low-inflation country (see Table 1) and perform several counterfactual experiments. Our main simulation results are as follows:

(i) Inflation has a large and negative effect on the growth rate of per capita income. The average low-inflation country could increase its per capita growth rate by 0.28 percentage points by following a zero percent inflation rate, which is several times larger than the growth effect in the literature (see the discussion below). For the average high-inflation country, the growth gains from eliminating inflation are much larger. Such a country could increase its per capita growth rate by almost 0.69 percentage points by following a zero inflation policy.

\footnotetext{
${ }^{3}$ Silviera and Wright (2006 and 2010) were the first to model innovation in a search and matching framework. They emphasize the importance of liquidity for the venture capital cycle. Chiu, Meh and Wright (2011) expand on the previous models to investigate the implications of search and bargaining frictions for growth. They characterize optimal policies to subsidize research and trade in ideas, but they do not discuss the effects of inflation on growth, welfare or financial sector size as we do. Waller (2011) integrates random matching and money in the neoclassical growth model.
} 
(ii) Reducing inflation to zero has sizable welfare gains. The average low-inflation country is willing to give up 2.3 percent of consumption, and the average high-inflation country is willing to give up 6.8 percent of consumption. ${ }^{4}$

(iii) Inflation has a large and negative effect on the size of the financial sector as measured by bank credit (see the definition in Table 1). For the average high-inflation country, the financial sector size is 36 percent lower than the one of the average low-inflation country.

In the next subsection, we contrast our results with those in the literature and explain why the microfounded model of the use of money in innovation is critical for the large welfare and growth effects of inflation.

\subsection{Relationship to the literature}

There is a large literature that studies the effects of inflation on welfare and growth. ${ }^{5}$ Numerous theoretical and empirical contributions have also investigated the relationship between finance and growth. ${ }^{6}$ In this paper, we focus on the provision of liquidity for the innovation sector, which is intuitively important for growth.

Traditional papers that study the effects of inflation on welfare abstract from longrun growth (e.g., Fisher, 1981; Lucas, 1981). ${ }^{7}$ More recently, Lagos and Wright (2005) study the welfare cost of inflation in a search and matching framework with bilateral bargaining. Their model generates significantly larger welfare costs of inflation than the previous literature due to the bargaining. However, they do not study the effects of inflation on economic growth. The models used to quantify the effects of inflation on growth typically combine a variant of an endogenous growth model with the assumption of a cash-in-advance constraint or a shopping technology that requires money. Examples are Gomme (1993),

\footnotetext{
${ }^{4}$ To calculate these welfare gains, we ask how much the representative household would pay in terms of consumption for reducing inflation from the observed level to zero.

${ }^{5}$ Recent surveys on the cost of inflation are Craig and Rocheteau (2005) and Gillman and Kejak (2005). Craig and Rocheteau focus on stationary models, while Gillman and Kejak focus on models with a balanced growth path. Gylfason and Herbertsson (2001) and Chari et al. (1996) compare various empirical studies. After reviewing the empirical evidence, Chari et al. suggest that a 10 percentage point increase in the average inflation rate is associated with a decrease in the average growth rate of between 0.2 and 0.7 percentage points. The robustness of this relationship is questioned, though. In particular, Bruno and Easterly (1998) point out that a positive correlation between inflation and real growth depends on the inclusion of high-inflation countries. To address this valid criticism, we eliminate all countries that experienced a hyperinflation.

${ }^{6}$ Early empirical studies on the relationship between finance and growth are Goldsmith (1969), Shaw (1973) and McKinnon (1973). More recent theoretical and empirical contributions are Greenwood and Jovanovic (1990), Levine (1991), King and Levine (1993a,b), Bencivenga and Smith (1993), Jones and Manuelli (1995), Acemoglu and Zilibotti (1997), Acemoglu et al. (2006), Aghion et al. (2010). It is not useful here to discuss the large number of empirical papers on this subject. For a literature review, we refer the reader to Levine (2005) or Boyd and Champ (2003). Rojas Breu (2011) studies the welfare effects of an improvement in productivity of the credit sector.

${ }^{7}$ Fisher (1981) and Lucas (1981) estimate the cost of inflation by calculating the appropriate welfare cost under the money demand curve. Fisher estimates the cost of increasing the rate of inflation from $0 \%$ to $10 \%$ to be $0.3 \%$ of income, and Lucas estimates it to be $0.45 \%$. For a discussion of these estimation procedures and more recent estimates see Lucas (2000) or Craig and Rocheteau.
} 
Ireland (1994), Dotsey and Ireland (1996), and Chari et al. In addition, the common approach in this literature is to model financial intermediation as a provider of consumption loans. The common result is that inflation has a negligible effect on the growth rate of per capita income (e.g., Gomme, Dotsey and Ireland, and Chari et al.). Thus, this literature concludes that inflation is not quantitatively important for growth, although it may affect welfare significantly (e.g., Dotsey and Ireland).

Table 2: Welfare and growth costs of inflation

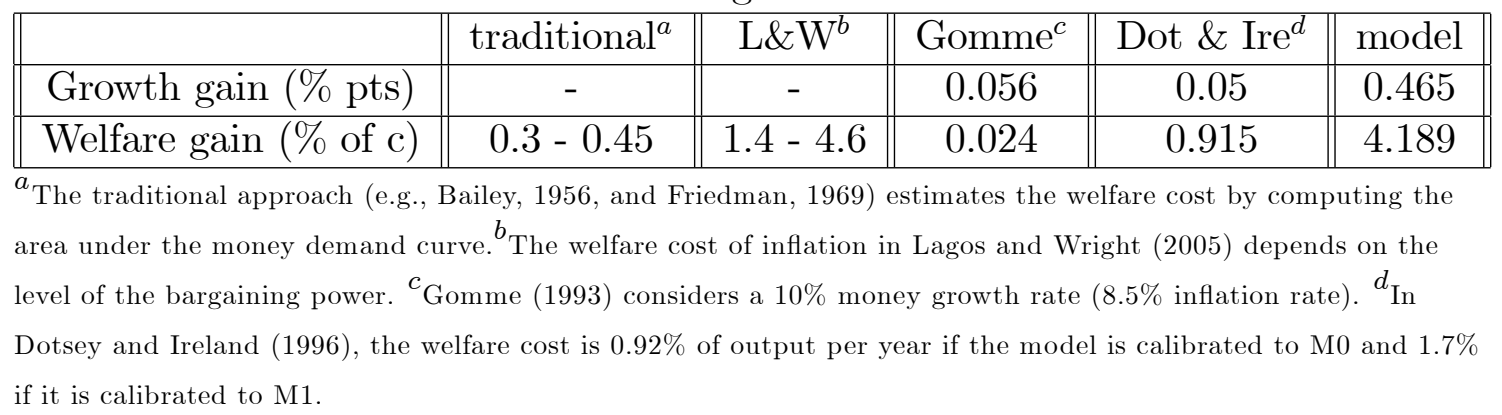

Table 2 contrasts the growth and welfare gains from reducing inflation to zero in our model with the effects in the literature. First, reducing the inflation rate from $10 \%$ to $0 \%$ increases the net rate of growth in per capita income by 0.465 percentage points in our model, which is substantially larger than the 0.05 percentage points in Dotsey and Ireland or the 0.056 percentage points in Gomme. Second, reducing inflation has a much larger welfare gain in our model than in the literature.

Let us emphasize that these large growth and welfare effects of inflation cannot be easily reproduced in a reduced-form model that introduces money via a cash-in-advance constraint in the innovation sector. In Section 5.2, we present such a cash-in-advance framework and find that inflation has only small growth effects (comparable to Gomme and Dotsey and Ireland).

\subsection{Is liquidity important for R\&D?}

In our model, a medium of exchange is needed for trade to take place in the innovation sector. This (micro-founded) requirement yields a direct channel through which monetary policy can affect productivity and growth in the economy. This modeling choice raises the question of whether liquidity is important for R\&D in the real economy.

The literature on $R \& D$ provides ample evidence that the $R \& D$ sector is cash-intensive. For example, the literature on corporate liquidity has pointed out that R\&D expenditures involve the use of cash (e.g., Brown and Petersen, 2011; McLean, 2011), and Opler et al. (1999) find in most of their regressions that cash holdings by U.S. publicly traded firms 
in the 1974-1994 period increase significantly with the R\&D-to-sales ratio. ${ }^{8}$ Bates et al. (2009) report that the average cash-to-assets ratio for U.S. industrial firms has more than doubled between 1980 and 2006. They claim that the increase in cash holdings can be ascribed to changes in firm characteristics, one of which is the rise in R\&D expenditures. Mikkelson and Partch (2003) study a sample of U.S. industrial firms with persistently high cash holdings and conclude that these firms are considerably more R\&D intensive than the average firm. More recently, Brown and Petersen report that publicly traded young R\&D firms in U.S. manufacturing rely extensively on cash holdings to carry out their R\&D spending and that, contrary to firms not reporting $R \& D$ expenses, $R \& D$ firms have considerably increased their cash holdings over the period 1982-2006. ${ }^{9}$

According to the literature on corporate finance, the main reason why R\&D firms hold large cash reserves is that they suffer from information frictions which limit their ability to resort to external finance. ${ }^{10}$ Assets held by R\&D firms are mainly intangible and subject to asymmetric information (e.g., Alam and Walton, 1995; Blazenko, 1987; Zantout, 1997). Thus, R\&D firms lack collateral value and are forced to greatly rely upon internal finance to fund their investments. ${ }^{11}$ Information frictions and limited collateral value have been used to explain why R\&D firms rely little on debt finance and instead fund most of their investments with cash reserves or equity. However, funding through equity is costly, especially for firms whose values are mostly determined by their growth opportunities and hence are severely exposed to asymmetric information frictions (e.g., Myers and Majluf, 1984; Himmelberg and Petersen, 1994; Kim et al., 1998). Moreover, because equity is not always available, firms tend to keep a large amount of equity proceeds in the form of liquid assets (e.g., Kim and Weisbach, 2008). McLean documents that the percentage of share issuance proceeds saved as cash by U.S. firms has substantially increased over the last few decades and argues that this trend can be explained by the increase in R\&D spending, among other precautionary motives.

In our model, traders in the innovation sector are anonymous and cannot pledge collateral, so that trade credit is not feasible. Furthermore, although agents have access to bank credit, they cannot borrow on a contingency basis, since banking activities take place before matches in the innovation sector are realized. Thus, agents must hold cash in order to trade in the innovation market. The goal of our model is to explore the link between the opportunity cost of holding cash, R\&D investments, and growth. For simplicity, we

\footnotetext{
${ }^{8}$ Most R\&D expenditures consist of wages and training costs of highly skilled workers (e.g., Lach and Schankeman, 1989; Himmelberg and Petersen, 1994; Brown and Petersen).

${ }^{9}$ Among others, John (1993) and McVanel and Peravalov (2008) also report a positive relationship between R\&D expenditures and corporate liquid holdings.

${ }^{10}$ As emphasized by this literature, holding liquid assets is costly for firms, because it entails an opportunity cost given by the liquidity premium. Firms are willing to face this cost only if other sources of funding may not be easily available or are relatively more costly (e.g., Opler et al.). See discussions and empirical evidence in Berger and Udell, 1990; Brown and Petersen; Brown et al., 2009; Himmelberg and Petersen; Mikkelson and Partch, among others.

${ }^{11}$ If the availability of external finance is uncertain, firms tend to hoard more cash if they face more important future growth opportunities (Almeida et al., 2004; John). The availability of investment opportunities for firms engaged in $R \& D$ activities is one of the factors which explain the relatively high cash-to-total assets ratios of R\&D firms (see Bates et al. and Opler et al).
} 
consider internal cash-flow as the only source of cash and do not model the process through which agents obtain their initial money holdings. Our approach can be justified by the fact that, regardless of how R\&D firms obtain their financing, they hold large amounts of cash or cash-like instruments as discussed above, so that they are exposed to monetary policy.

\section{The Model}

A discrete-time economy is populated by a unit measure of households. A household has a unit of members who share consumption and regard the household's utility as the common objective. $^{12}$ Household members are engaged in four activities: searching and working in the innovation sector, producing final goods, working in the financial sector, and leisure.

Each member is endowed with one unit of time per period, which he can divide between work and leisure. If a member works in either final-goods production $(h)$ or financial intermediation $(k)$, the required time input is 1 . If a member is a potential innovator $(l)$, his working time consists of the time searching and, if matched, the time working in the innovation sector. The time input required for search in the innovation sector is $\rho$, where $\rho \in(0,1)$ is a constant, and the time working in the innovation sector is $y$. For the baseline model, we assume that $y$ is a constant and equal to $y=1-\rho$, so that the total time input of an innovator is $1 .{ }^{13}$ The utility of enjoying one unit of leisure is $\theta$. Thus, the household's lifetime utility is:

$$
\sum_{t=1}^{\infty} \beta^{t-1}\left\{u\left(q_{t}\right)+\theta\left(1-h_{t}-k_{t}-l_{t} e[\rho+\sigma(1-\rho)]\right)\right\} .
$$

Here $q_{t}$ is the quantity of final goods consumed by the household. The parameter $e$ is the probability that a potential innovator has access to the innovation market (to be explained later) where he searches for a match. The household's total time searching is $l_{t} e \rho$. The parameter $\sigma \in(0,1)$ is the probability of a single coincidence meeting in the innovation sector. The household's total time working in the innovation sector is then $\sigma l_{t} e(1-\rho)$. Finally, the household's total leisure time is $1-h_{t}-k_{t}-l_{t} e[\rho+\sigma(1-\rho)]$. This precise accounting of time for each activity allows us to match the model to time-use data as described later. The discount factor is $\beta \in(0,1)$ and the discount rate is $R \equiv \beta^{-1}-1$.

We pick an arbitrary household as the representative household and use lower-case letters to denote its decisions. The decisions of other households and the aggregate variables are denoted as upper-case letters. The representative household takes all upper-case vari-

\footnotetext{
${ }^{12}$ The device of a household is used here to maintain tractability, as it enables us to smooth the matching risk within a household (to be described below) and hence to obtain a degenerate distribution of money holdings across households. See Shi (1997).

${ }^{13}$ In the baseline model, we assume that a matched innovator works a fixed amount of time. In Section 6.1 , we relax this assumption and let households choose the amount of innovation time, $y$, that a member buys in the innovation market. This case allows us to distinguish between the growth effects of inflation that arise via the extensive margin (how many members to send to the innovation sector) and the effects that arise via the intensive margin (how much time a member works in the innovation sector).
} 
ables as given. For the remainder of the paper, we suppress the time index $t$ and indicate the next period's variable by the subscripts +1 .

A household uses labor $h$ to produce final goods according to the production function, $q(h, a)$, where $a$ is the household's productivity in the final-goods sector. Final goods are perishable between periods. In the innovation sector, a household has specialized skills, which are no use to the household, but can be used by some other households as an input into the innovation process. Productivity in the final-goods sector is determined by the time used for innovation as follows. If $i$ is the amount of time that enters the innovation process in the current period, then the household's productivity in the next period will be

$$
a_{+1}=a[1+f(i)]
$$

Let us refer to the function $f(i)$ as the innovation function and to $a$ as knowledge capital.

For simplicity, we assume that the utility function, $u$, the production function of final goods, $q$, and the innovation function, $f$, have the following standard forms:

$$
\begin{gathered}
u(q)=\ln (q), \quad q(h, a)=a h^{\eta}, \quad f(i)=f_{0} i^{\chi}, \\
\eta, \chi \in(0,1), f_{0}>0 .
\end{gathered}
$$

The innovation sector, referred to as the innovation market, is decentralized. Individuals in the innovation market are randomly matched in pairs. In any given match, the first agent can make use of the innovation skills belonging to the second agent with probability $\sigma \in(0,1)$; with the same probability, the second agent can make use of the innovation skills belonging to the first agent. No double-coincidence occurs. Let us label the agent who can use the other agent's innovation skills as the buyer, and the other agent as the seller. The buyer makes a take-it-or-leave-it offer to the seller, which consists of an amount of money to be paid by the buyer for $1-\rho$ units of time to be worked by the seller.

To capture the demand for and supply of liquidity in the innovation market, we make two additional assumptions about this market. First, we assume that in the innovation sector agents are anonymous and no form of record-keeping is feasible. For transactions to take place in this market, a medium of exchange is needed. This medium is fiat money, a perfectly storable object which is intrinsically worthless. Second, we assume that only a fraction $e$ of a household's potential innovators can enter the innovation market in any given period and that a potential innovator realizes whether he can enter the market after he is given money. As a result, those who cannot enter the innovation market have "idle" money which they would like to lend to earn interest, and those who can enter the market demand more liquidity and are willing to pay for it. One way to interpret this assumption is that innovation skills or the ability to use other agents' innovation skills do not always arise easily. As a result, a fraction of the potential innovators learn that they have no marketable innovation skills or no use of other agents' innovation skills and do not enter the innovation sector. This assumption generates heterogeneity in the need for liquidity.

Borrowing and lending is done through financial intermediaries that have free entry into the financial sector. We assume that financial intermediaries have no ability to keep records on transactions in the innovation market. This assumption prevents banks from issuing 
credit that supersedes money or directly intermediating trades in the innovation market. However, banks are able to keep financial records on monetary loans and repayments, at a cost. So, borrowing and lending are in terms of money. If a buyer fails to repay a loan, the bank can confiscate money holdings of the buyer's household, which ensures that loans are always repaid. Banks take the deposit rate as given and compete in the loan market. Depositors have perfect information about the banks' financial state and trading histories, which induces the banks to always repay the depositors. ${ }^{14}$

The production function in the financial sector is such that the labor input required to create and administer loans is proportional to the number of loans. ${ }^{15}$ Since only a fraction $e$ of the potential innovators can enter the innovation market, the number of loans is $e L$, where $L$ is the aggregate measure of innovators per household. The aggregate measure of workers in the financial sector per household is $K$. Thus, the technology of financial intermediation implies:

$$
e L=\phi K
$$

where $\phi>0$ is a constant measuring financial productivity. We refer to the case $\phi \rightarrow \infty$ as a perfect loan market; i.e., one in which financial intermediation requires no resources.

Financial intermediaries take the loan rate, $r_{\ell}$, the deposit rate, $r_{d}$, and the nominal wage rate, $w$, that is paid to household members working in the financial sector as given. There is no strategic interaction among financial intermediaries or between financial intermediaries and agents. In particular, there is no bargaining over the terms of the loan contract. Instead, these terms will be determined by the free entry of intermediaries, which drives each financial intermediary's profit to zero.

Finally, to simplify the analysis and to focus on the main mechanism of the paper, we assume for now that there is no need for a medium of exchange in the market for final goods. ${ }^{16}$ We will directly invoke the result that a household's consumption of final goods is equal to the quantity produced in a symmetric equilibrium. That is, $q=q(h, a)$.

For clarity, let us describe the sequence of events in a period as follows. First, at the beginning of the period, each household chooses the allocation of its members into the four groups, and divides its holdings of money among the innovators. Second, the potential innovators leave the household. Each potential innovator learns whether he can enter the innovation market and decides whether to borrow from or lend to financial intermediaries. Third, after borrowing and lending, potential innovators are matched randomly and bilaterally, and they trade money for innovation time. The innovation time purchased from other households is used as the input in the innovation process to increase future productivity. Simultaneously, in the final-goods market, the producers produce and sell

\footnotetext{
${ }^{14}$ Our assumptions of perfect monitoring of the borrowers by the banks and of the banks by the depositors simplify the analysis and enable us to focus on growth. For a relaxation of this assumption, see Berentsen et al. (2007).

${ }^{15}$ We can generalize this specification by adding a component of the labor requirement for financial intermediation that is proportional to the real stock of loans. However, the part of the cost that is independent of the size of the loan is important for the results.

${ }^{16}$ However, this assumption is not necessary for our results. In Section 6.2, we relax this assumption by assuming that this market also requires money in transactions, and show that inflation generates growth and welfare effects that are larger than those in the baseline formulation.
} 
the final goods, and also purchase final goods for the household's consumption. Fourth, the members bring money and purchased goods back to the household, and the household consumes the final goods. Before the period ends, the household repays the loans, receives interest payments on its deposits, and receives a lump-sum monetary transfer from the government.

Like many models of endogenous growth (e.g., Lucas, 1988), our model generates longrun growth through the non-diminishing marginal productivity of $a$ in the innovation process. In particular, the law of motion and the production function $q(h, a)$ are both linear in $a$. The allocation of time between different sectors is the important dimension along which inflation affects economic activities in our model. The new feature of the model is decentralized exchange in the innovation market. This feature generates the demand for liquidity and the need for financial intermediation, which establishes the link between monetary policy and real growth.

\subsection{The social planner's allocation}

To provide a benchmark against which to measure the efficiency of the equilibrium, let us first consider the allocation of a social planner. Assume that the social planner can dictate all quantities, but is subject to the same matching frictions in the innovation process as the market is. The social planner does not need a credit market, and so $k=0$. Denote the planner's allocation as $S=\{l, h, q\}$, where $l$ is the fraction of potential innovators, $h$ the fraction of agents who produce final goods, and $q$ the quantity of final goods produced and consumed by a household. Denote the maximized social welfare function as $W(a)$. Then, the planner's allocation solves:

$$
W(a)=\max _{S}\left\{u[q(h, a)]+\theta\{1-h-l e[\rho+\sigma(1-\rho)]\}+\beta W\left(a_{+1}\right)\right\}
$$

subject to the following constraints:

$$
\begin{aligned}
a_{+1} & =a[1+f(i)] \\
i & =\operatorname{\sigma el}(1-\rho) .
\end{aligned}
$$

The first term in the welfare function is a household's total utility from consumption, where we have substituted the result that the quantity of final goods consumed is equal to the quantity produced. The second term is the total utility of leisure in the household, where $e l$ is the fraction of agents who enter the innovation market, and $\sigma$ is the probability that each potential innovator has a match in which he works $1-\rho$ units of time. The law of motion of productivity is given by (4). The amount of time input in the innovation process is given by (5), because $\sigma e l$ is the fraction of agents who work $1-\rho$ units of time.

Denote the solution to the above problem by adding the superscript $s$ to the variables. Define a balanced growth path of the social optimum as such that the growth rate of $a$ is constant, while the levels of $(h, l)$ are constant. With the functional forms in $(2)$, we can establish the following proposition (the proof of which is straightforward and, hence, omitted): 
Proposition 1 There exists a unique balanced growth path of the social optimum, which is the solution to (5), and the following equations:

$$
\begin{aligned}
\eta / h^{s} & =\theta \\
R\left[1+f\left(i^{s}\right)\right] & =\frac{f^{\prime}\left(i^{s}\right) i^{s}}{\theta l e[\rho+\sigma(1-\rho)]}
\end{aligned}
$$

The socially efficient rate of growth is:

$$
g^{s}=1+f\left(i^{s}\right) .
$$

Equations (6) and (7) come from the first-order conditions of $h$ and $l$, respectively; they say that the marginal benefit of allocating an agent to the final-goods market or the innovation market must be equal to the marginal utility of leisure.

\section{Equilibrium and the Balanced Growth Path}

In this section, we first present the household's decision problem and, then, derive the equilibrium allocation on the balanced growth path.

\subsection{The representative household's decisions}

At the beginning of a period, the household chooses the measure of potential innovators, $l$, producers of final goods, $h$, and financial intermediaries, $k$. It allocates money evenly among the potential innovators, each receiving $m / l$ units of money. The household also chooses the quantity of final goods to be produced and purchased, $q$, and the amount of money, $x$, that a buyer in the innovation market will offer to a seller in a match. After leaving the household, potential innovators face the probability $e$ of being able to enter the innovation market. Those who can enter may borrow money from the financial intermediary, with $b_{\ell}$ being the nominal amount of borrowing. Those who cannot enter the market may lend money to the financial intermediary, with $b_{d}$ being the nominal amount of lending. Moreover, the household chooses future holdings of money, $m_{+1}$, and the future productivity, $a_{+1}$. The decision variables of the household are then:

$$
z \equiv\left[q, l, k, h, x, b_{\ell}, b_{d}, m_{+1}, a_{+1}\right] .
$$

Let $m$ denote a representative household's holdings of money at the beginning of a period. The household's value function is $V(a, m)$. Define:

$$
\omega \equiv \beta \frac{\partial V\left(a_{+1}, m_{+1}\right)}{\partial m_{+1}} \quad \text { and } \quad \lambda \equiv \beta \frac{\partial V\left(a_{+1}, m_{+1}\right)}{\partial a_{+1}} .
$$

The variable $\omega$ is the shadow value of money of the next period, and $\lambda$ is the shadow value of future productivity, both of which are discounted to the current period. 
The representative household's problem is to choose $z$ to solve the following problem:

$$
V(a, m)=\max _{z}\left\{u[q(h, a)]+\theta\{1-k-h-l e[\rho+\sigma(1-\rho)]\}+\beta V\left(a_{+1}, m_{+1}\right)\right\}
$$

subject to the following constraints:

$$
\begin{aligned}
b_{d} & \leq \frac{m}{l}, \\
x & \leq \frac{m}{l}+b_{\ell}, \\
\Omega x & \geq \theta(1-\rho), \\
a_{+1} & =a+a f[\operatorname{\sigma el}(1-\rho)], \\
m_{+1}-m & =\operatorname{\sigma el}(X-x)+l\left[(1-e) b_{d} r_{d}-e b_{\ell} r_{\ell}\right]+w k+T .
\end{aligned}
$$

In the objective function, the first term is the utility of consuming final goods, where we have again used the result that $q=q(h, a)$. According to (10), a depositor cannot deposit more money than the amount he is given by the household. The next two conditions, (11) and (12), are the constraints on the offer that will be made by a buyer in the innovation market. The constraint (11) specifies that a buyer cannot offer more money than his money balance, which consists of the amount given by the household, $m / l$, and the amount borrowed, $b_{\ell}$. The constraint (12) says that the offer must induce the seller to work $1-\rho$ hours; that is, since $\Omega$ denotes the marginal value of money to the seller's household, the value of the money received by the seller, $\Omega x$, must be at least as high as the disutility of working $1-\rho$ hours. ${ }^{17}$

The law of motion of productivity is (13), where the inputs are the amount of time that the household's buyers obtain in the innovation market, $i=\sigma e l(1-\rho)$. The law of motion of the household's money balance is (14). The term $\sigma e l(X-x)$ is net money receipts from trading in the innovation market, since a fraction $\sigma e$ of potential innovators spend an amount $x$ to buy innovation time, and a fraction $\sigma e$ of them receive an amount $X$, when selling innovation time. The term $l\left[e b_{d} r_{d}-(1-e) b_{\ell} r_{\ell}\right]$ is net money receipts from borrowing and lending, since a fraction $e$ of potential innovators borrow money and a fraction $1-e$ of them deposit money, where $r_{d}$ is the deposit rate and $r_{\ell}$ the loan rate. Finally, the household receives wage payments for workers in the financial sector, $w k$, and lump-sum monetary transfers from the government, $T$.

We will examine an equilibrium in which the deposit rate is positive; i.e., $r_{d}>0$. In this case, a lender will deposit all his money balance with the financial intermediary, and so (10) holds as an equality. Moreover, if the loan rate is positive, a borrower will never borrow more than what he will need in a match. As a result, a buyer in the innovation market will offer his entire money balance in a match; that is, (11) holds as an equality. The other constraint on the offer, (12), also holds as an equality, because it is not optimal for a buyer to leave a positive surplus to the seller under the assumption of take-it-orleave-it offers. Since (10) through (12) all hold as equalities, we can use them to solve for

\footnotetext{
${ }^{17}$ Note that it is the household that chooses the offer $x$, taking into account all the constraints (i.e., (11) and (12)) that a buyer will face in a match. A buyer simply implements this offer. Thus, there is no need to specify a separate bargaining problem for each buyer.
} 
$\left(x, b_{\ell}, b_{d}\right)$. Substituting the solutions into the objective function and the other constraints, we can derive the following optimal conditions of $(k, h, l)$ and the envelope conditions of $(a, m)$ :

(i) Optimal choices of the number of financial intermediaries, $k$, and final-goods producers, $h$ :

$$
\omega w=\frac{\eta}{h}=\theta
$$

The term $\omega w$ is the value of wages (in terms of utility) earned by workers in the financial sector, and the term $\eta / h$ is the marginal value of consumption goods produced by an additional producer. The above condition requires that the marginal benefit of increasing $k$ or $h$ should be equal to the marginal utility of leisure, which is $\theta$.

(ii) Optimal choice of the number of innovators, $l$ :

$$
\lambda a f^{\prime}(i) \sigma(1-\rho)=\theta\left[\rho+\left(r_{\ell}+\sigma\right)(1-\rho)\right]
$$

Allocating an additional member to be a potential innovator has the following benefits and costs. First, with probability $\sigma$, a potential innovator who enters the innovation market is a buyer and acquires $1-\rho$ innovation time, which increases the household's productivity in the next period by $a f^{\prime}(i)(1-\rho)$. Thus, the expected benefit of an innovator in the market is given by the left-hand side of (16). Second, with probability $\sigma$, the potential innovator is a seller and works $1-\rho$ units of time. The expected cost in terms of utility is $\sigma \theta(1-\rho)$. Third, the expected cost of borrowing incurred by an additional innovator is $\omega r_{\ell} x$, which is equal to $\theta r_{\ell}(1-\rho)$ after substituting $x=\theta(1-\rho) / \Omega$ and $\Omega=\omega$. Finally, by searching, each innovator foregoes the value of leisure, which is $\theta \rho$. The sum of $\theta \sigma(1-\rho), \theta r_{\ell}(1-\rho)$, and $\theta \rho$ equals the right-hand side of $(16) .{ }^{18}$

(iii) The envelope conditions for $a$ and $m$ :

$$
\begin{gathered}
\frac{\lambda_{-1}}{\beta}=\lambda[1+f(i)]+\frac{1}{a} \\
\frac{\omega_{-1}}{\beta}=\omega+\omega\left[(1-e) r_{d}+e r_{\ell}\right] .
\end{gathered}
$$

These conditions state that the current value of an asset $(a$ or $m$ ) is equal to the future value of the asset plus the additional value of the asset in the current exchange. According to (17), a marginal unit of productivity results in $[1+f(i)]$ units of future productivity, the value of which is $\lambda[1+f(i)]$. In addition, a marginal unit of productivity saves the production cost of final goods, whose value in terms of utility is $u^{\prime}(q) h^{\eta}=1 / a$. Similarly, in (18), an additional unit of money (in the hands of an innovator) allows the innovator to earn the deposit rate when the innovator cannot enter the innovation market, and to save the cost of borrowing when the innovator can enter the innovation market.

\footnotetext{
${ }^{18}$ Increasing $l$ also reduces the amount of money each innovator has. However, the negative effect of this reduction cancels with the positive effect generated by the presence of more innovators. Note also that the value of money paid by a buyer cancels with the value of money obtained by a seller, because $X=x$ in a symmetric equilibrium.
} 


\subsection{Symmetric Equilibrium and the Balanced Growth Path}

There is free entry of financial intermediaries. Let $B_{\ell}$ be the economy-wide average of the amount of borrowing per borrower, and $B_{d}$, the economy-wide average of the amount of lending per lender. Since a household has a measure $e L$ of borrowers and a measure $(1-e) L$ of depositors, the aggregate amount of loans and deposits per household is $L e B_{\ell}$ and $L(1-e) B_{d}$, respectively. Since a financial intermediary hires a measure $K$ of workers and pays the nominal wage $w$, the nominal cost of financial intermediation is $w K$. The intermediary covers this cost with a spread between the loan rate, $r_{\ell}$, and the deposit rate, $r_{d}$. Therefore, the intermediary's profit is

$$
L\left[r_{\ell} e B_{\ell}-r_{d}(1-e) B_{d}\right]-w K .
$$

With free entry of intermediaries, the above profit is zero, and so

$$
r_{\ell} e B_{\ell}-r_{d}(1-e) B_{d}=w K / L .
$$

We focus on the monetary equilibrium which is symmetric in the sense that the decisions are the same for all households. Also, as stated earlier, we focus on the equilibrium where the deposit rate and the loan rate are both positive. Throughout this paper, monetary policy is such that monetary transfers maintain the gross rate of money growth at a constant level $\gamma \geq \beta$.

We have already used the market clearing condition for final goods: $q=q(h, a)$. Note that, since the value of money in terms of utility is $\omega$, the nominal price of final goods is:

$$
p=\frac{u^{\prime}(q)}{\omega}=\frac{1}{\omega q} .
$$

With the above focus, a monetary equilibrium consists of the representative household's decisions, $z$; other household's decisions, $Z$; and interest rates, $r_{d}>0$ and $r_{\ell}>0$, which meet the following requirements: (i) $z$ solves the representative household's maximization problem above; (ii) the decisions are symmetric across households: $z=Z$; and (iii) the final-goods market clears and each financial intermediary makes zero profit.

A balanced growth path is defined as an equilibrium in which productivity, $a$, grows at a constant gross rate $g$, and interest rates are non-negative and finite constants (i.e., $\left.0 \leq r_{d} \leq r_{\ell}<\infty\right)$. It is clear from (13) that

$$
g=1+f(i) .
$$

Lemma 1 The balanced growth path has the following properties: (i) $l, k$ and $h$ are constants in $(0,1)$; (ii) q grows at rate $g$; (iii) the marginal value of money, $\omega$, decreases at rate $\gamma$; and (iv) the marginal value of productivity, $\lambda$, falls at rate $g$. Moreover, interest rates, $r_{d}$ and $r_{\ell}$, satisfy:

$$
\begin{aligned}
\frac{\gamma}{\beta} & =1+e r_{\ell}+(1-e) r_{d} \\
1 & =\left(r_{\ell}-r_{d}\right)(1-e)(1-\rho) \phi .
\end{aligned}
$$


On the equilibrium balanced growth path, $\{h, l, k\}$ are determined by:

$$
\begin{aligned}
\theta & =\frac{\eta}{h} \\
R[1+f(i)] & =\frac{f^{\prime}(i) i}{\theta e l\left[\rho+\left(\sigma+r_{\ell}\right)(1-\rho)\right]} \\
\phi k & =e l .
\end{aligned}
$$

The proof of this Lemma (which is omitted here) involves straightforward manipulations of the equilibrium conditions derived earlier. Equation (22) comes from (18), which is the envelope condition of money holdings. Equation (23) comes from the zero-profit condition of intermediation, (19). Equation (24) comes from the first-order condition of $h$ stated in (15). Equation (25) comes from the first-order condition for $l,(16)$, and from the envelope condition of $a$, (17). Finally, (26) replicates the production function of the financial sector.

To relate the monetary equilibrium allocation to the planner's allocation, it is useful to compare (25) with (7). It is evident that the interest rate on loans $r_{\ell}$ creates a wedge that lowers the total time worked in the innovation market. In steady-state, increasing inflation increases the interest rate on loans, and so $l$ and $g$ fall.

\section{Quantitative Analysis}

In this section, we calibrate the model to quantify the welfare and growth effects of inflation.

\subsection{Calibration}

The functions $u(q), q(h, a)$ and $f(i)$ have the forms in (2). ${ }^{19}$ The parameters to be identified are as follows: (i) preference parameters: $(\beta, \theta, \rho)$; (ii) technology parameters: $\left(\eta, f_{0}, \chi, \sigma, \phi, e\right)$; (iii) policy parameters: the money growth rate $\gamma$. To identify these parameters, we use data from low-inflation countries if possible, and if not, we use US-data. The use of the balanced growth path in the calibration is reasonable, because low-inflation countries are typically developed countries. The model period is set to one year. Table 3 lists the identification restrictions and the identified values of the parameters.

The inflation rate and per capita growth rate of the model match the ones of the average low-inflation country, which are $5.4 \%$ and $3.12 \%$, respectively. The deposit rate matches the average annualized interest rate on the US 3-month deposit certificates from $1970-1999 .{ }^{20}$ The real interest is set to $4.2 \%$.

\footnotetext{
${ }^{19} \mathrm{~A}$ more general form of $q(h, a)$ is $q(h, a)=a h_{0} h^{\eta}$ with $h_{0}>0$. We set the scale parameter $h_{0}$ to 1 , because it affects only the initial level of $a$, which is irrelevant for what follows.

${ }^{20} \mathrm{~A}$ certificate of deposit is a time deposit. It is insured and is thus virtually risk-free. Since we have no default in our model, we use a risk-free rate. Alternatively, we could have used the average of the shortterm commercial paper rate which is 7.66\% for 1970-1995 (Friedman and Schwartz, 1982; and Economic Report of the President, 1999).
} 
Table 3: Calibration

\begin{tabular}{|c|c|c|}
\hline parameters & values & identification restrictions \\
\hline$\beta$ & 0.96 & real interest rate $=0.042$ \\
\hline$\gamma$ & 1.087 & inflation rate $=0.054$ \\
\hline$e$ & 0.96 & mean fraction of borrowing of R\&D firms $=0.04$ \\
\hline$\eta$ & 0.64 & return on deposit certificates $=0.075$ \\
\hline$\theta$ & 3.4 & labor share $=0.64$ \\
\hline$\rho$ & 0.115 & average hours schooling per week $=2.97$ \\
\hline$\sigma$ & 0.052 & R\&D employment/total employment $=0.055$ \\
\hline$\phi$ & 474 & loan officers/total employment $=0.0025$ \\
\hline$\chi$ & 0.31 & working time/total time $=0.2$ \\
\hline$f_{0}$ & 0.127 & per capita growth rate $=0.031$ \\
\hline
\end{tabular}

As in King and Rebelo (1993), 20\% of the total time is allocated to working. In our model, working consists of producing final goods, working in the innovation sector, and working for financial intermediaries. According to a report on occupational employment and wages by the Bureau of Labor Statistics (BLS, 2007), the fraction of loan officers to total employment in May 2005 was $0.0025 .{ }^{21}$ According to the occupational employment statistics survey ${ }^{22}$ the individuals employed in science and engineering occupations was $5.5 \%$ of the total workforce in May 2007. In Ramey and Francis (2009), the average hours schooling per week are 2.97, and the average hours worked per week are 21.71 (average of 1965-2005). Since we have normalized total working hours to 0.2 in the model, the corresponding model hours for schooling are 0.0274. Brown and Petersen find that the mean fraction of debt to total assets of young R\&D firms is $4 \%$ (Table 1, p. 700). ${ }^{23}$ Finally, a labor share of 0.64 is standard. ${ }^{24}$

As discussed further below, the key to understanding the large growth effects of inflation is search as represented by the matching probability $\sigma$ and the search time $\rho$. The target "average hours of schooling per week", among other targets, pins down the search time $\rho$. It captures the fact that a fraction of the cost of the innovation process is non-random and arises from the time spent in education or from learning-by-doing. ${ }^{25}$ It complements our target "R\&D employment to total employment", which, among other targets, pins down

\footnotetext{
${ }^{21}$ According to this report, in May 2005, 332,690 people were working as loan officers and total employment in the economy was $130,307,850$. The implied ratio 0.0025 is similar to the number 0.0028 used by Dotsey and Ireland.

${ }^{22}$ Statistical Abstract of the U.S. 2009, Table 788.

${ }^{23}$ They classify a firm as young for the first 15 years following the year it first appears in Compustat with a stock price.

${ }^{24}$ We provide step-by-step instructions of our calibration strategy in the supplementary material.

${ }^{25}$ In our model, only potential innovators spend time in education, whereas our target "average hours of schooling per week" corresponds to the average time spent of the entire population. Since the typical R\&D employee spends more time in education than the average citizen, our target is rather low. Increasing the value of the target would result in a higher value of $\rho$ (see the calibration procedure in the supplementary material), and, as shown in Section 5, a higher value of $\rho$ generates larger growth effects of inflation.
} 
the matching frictions $\sigma$. Here, the matching friction captures the fact that the innovation process is random and that not all potential innovators can successfully contribute to a household's increase in productivity.

Table 4: Effects of inflation on growth and the financial sector

\begin{tabular}{l||c||c||c|c||c|c||c|c|c||}
\hline \multicolumn{1}{||c||}{} & \multicolumn{2}{c||}{ Inflation } & \multicolumn{2}{c||}{ Growth } & \multicolumn{2}{c||}{ Size of FS } & \multicolumn{3}{c||}{ Margin } \\
\hline & Data & Model & Data & Model & Data & Model & Data & Model & Model I \\
\hline Low $^{b}$ & 0.054 & 0.054 & 0.0312 & 0.0312 & 1.00 & 1.00 & 1.00 & 1.00 & 1.00 \\
\hline Mid & 0.088 & 0.088 & 0.0175 & 0.0298 & 0.56 & 0.87 & 1.09 & 1.00 & 1.19 \\
\hline High & 0.169 & 0.169 & 0.0165 & 0.0270 & 0.42 & 0.64 & 1.71 & 1.00 & 1.64 \\
\hline
\end{tabular}

Table 4 compares the model's predictions on inflation, the growth rate, the size of the financial sector (FS) and the interest margin with the data. For the average low-inflation country, the growth rate has the same value in the model as in the data, because it is used as a target in the calibration. We also set the inflation rates of mid- and high-inflation countries to match the data. Our model does a reasonable job in replicating the change in the size of the financial sector. When inflation increases from low to high levels, the per capita growth rate and the size of the financial sector fall in the model as well as in the data, although it falls more sharply in the data.

Our baseline model cannot replicate the change in the interest margin, since, from (23), the interest spread is independent of inflation. In Section 6.1, where we enhance the baseline model with an intensive margin (i.e., households obtain the choice of how many hours to work in a match), the interest-rate margin is increasing in inflation and matches the increase of the interest-rate margin observed in the data (see the column labeled Model I in Table 4).

Note that inflation in our model can only explain a fraction of the observed fall in per capita growth and the fall in the size of the financial sector. For example, in the data per capita growth in the average high-inflation country is about $45 \%$ lower than in the average low-inflation country. The model only predicts a decrease of about $13.5 \%$ (from $3.12 \%$ to $2.7 \%$ ). This is not surprising, as one would expect that the two country types differ in many other characteristics that also affect per capita growth.

\subsection{Welfare analysis}

We now quantify the cost of inflation by focusing on the balanced growth path. Denote the net rate of inflation as $\pi$. Following the literature (e.g., Lucas, 2000, and Lagos and Wright), we measure the welfare cost of inflation at $\pi$ relative to $\pi^{\prime}$ by asking how much consumption (in percentage) agents would be willing to give up in order to change inflation from $\pi$ to $\pi^{\prime}$. To express this measure formally, let $\pi$ be any given inflation rate and $\Delta$ any 
fraction. Slightly abusing an earlier notation, we write the household's expected discounted utility under $(\pi, \Delta)$ as:

$$
V(\pi, \Delta)=\sum_{t=1}^{\infty} \beta^{t-1}\{\ln (\Delta q)+\theta\{1-k-h-l e[\rho+\sigma(1-\rho)]\}\}
$$

where the quantities $(q, l, k, h)$ take their values on the equilibrium balanced growth path at $\Delta=1$. Note that $q$ is not stationary on the balanced growth path; rather, it grows at the gross rate $g$. Expressing $q_{t}=q_{1} g^{t-1}$, we can rewrite the expected utility as

$$
V(\pi, \Delta)=\frac{1}{1-\beta}\left\{\ln \left(\Delta q_{1}\right)+\frac{\beta}{1-\beta} \ln (g)+\theta\{1-k-h-l e[\rho+\sigma(1-\rho)]\}\right\}
$$

The welfare cost of inflation at $\pi$ relative to $\pi^{\prime}$ is the value of $(1-\Delta)$ that solves $V\left(\pi^{\prime}, \Delta\right)=$ $V(\pi, 1)$.

\subsection{The growth and welfare effects of inflation}

Consider the three groups of countries that differ in the inflation rate; i.e., the countries with low inflation $(5.4 \%)$, medium inflation $(8.8 \%)$, and high inflation $(16.9 \%)$. For each of these groups, Table 5 reports the key variables on the balanced growth path. Also, Table 5 reports the gains in welfare and the growth rate from moving to zero inflation.

As Table 5 shows, the time spent in innovation decreases significantly after an increase in inflation. As a result, the growth rate is decreasing in inflation, and this negative effect of inflation on growth is large. For the average medium-inflation country, reducing its inflation from the average $(8.8 \%)$ to zero increases the long-run growth rate by 0.42 percentage points. For the average high-inflation country $(16.9 \%)$, reducing its average inflation to zero increases the long-run growth rate by 0.69 percentage points. These effects of inflation on growth fall into the range of empirical estimates obtained from cross-country studies (see the references in the Introduction). They are much larger than the growth effects of inflation found in the literature. In Gomme, and Dotsey and Ireland, for example, reducing inflation to zero in a similar experiment increases growth by only 0.05 percentage points. 
Table 5: Effects of inflation in the baseline model

\begin{tabular}{|l|l|l|l|l|}
\hline & \multicolumn{4}{|c|}{ inflation } \\
\hline & $0 \%$ & $5.4 \%$ & $8.8 \%$ & $16.9 \%$ \\
\hline time innovating & 0.01446 & 0.011 & 0.00948 & 0.00698 \\
\hline time in finance & 0.00066 & 0.0005 & 0.00043 & 0.00032 \\
\hline time working & 0.20361 & 0.2 & 0.19841 & 0.1958 \\
\hline \multicolumn{5}{|l|}{} \\
\hline net interest margin & 0.05957 & 0.05957 & 0.05957 & 0.05957 \\
\hline bank credit (ratio) & 1.29886 & 1 & 0.8662 & 0.64368 \\
\hline \multicolumn{5}{|l|}{} \\
\hline R\&D / GDP & 0.04669 & 0.03594 & 0.03113 & 0.02314 \\
\hline \multicolumn{5}{|l}{} \\
\hline growth gain (\% pts) ${ }^{a}$ & 0 & 0.27701 & 0.41828 & 0.68851 \\
\hline welfare gain (\% of c) & 0 & 2.26704 & 3.68897 & 6.82773 \\
\hline
\end{tabular}

${ }^{a}$ Growth gain in percentage points from reducing the inflation rate to $0 \%$. ${ }^{b}$ Welfare gain as a percentage of consumption from reducing the inflation rate to $0 \%$.

Higher rates of inflation also affect the financial market considerably. Table 5 shows that the size of the financial market relative to the economy decreases significantly with inflation, as indicated by the large reduction in the ratio of loans to GDP. For the mediuminflation country, the ratio of loans to GDP is only $87 \%$ of the ratio for the low-inflation country, and for the high-inflation country this ratio is $64 \%$ of the ratio for the low-inflation country.

Inflation has large welfare effects. For the low-inflation country, the welfare gain from reducing inflation from the historical mean $(5.4 \%)$ to zero is $2.3 \%$ of consumption. For the medium-inflation country, the welfare gain from reducing inflation from the historical mean $(8.8 \%)$ to zero is $3.7 \%$ of consumption. For the high-inflation country, the corresponding welfare gain is $6.8 \%$ of consumption. These welfare effects are considerably larger than the ones obtained in the literature (e.g., Dotsey and Ireland), because inflation has a much larger negative effect on growth in our model than in the literature.

The growth effects of inflation are large, because inflation reduces the members allocated to the innovation sector substantially. For example, for the average high-inflation country, the time innovating is less than $65 \%$ of the time of the average low-inflation country. This is also reflected by the much lower R\&D/GDP ratio which is $2.31 \%$ for the average high-inflation country versus $3.59 \%$ for the average low-inflation country. ${ }^{26}$

\footnotetext{
${ }^{26}$ Note that our R\&D/GDP ratio for the average low-inflation country is higher than the average of R\&D expenditure as a percentage of GDP for the US, which is 2.62\% for 1981-2006 (Factbook 2008: Economic, Environmental and Social Statistics, OECD). The reason is that we calibrate our model to the fraction of individuals employed in science and engineering, which is $5.5 \%$.
} 


\section{The Role of Search and Comparison with CIA}

Why do we need microfoundations, and do they matter for any substantive results? These and related questions are often raised when we present a search-and-bargaining framework in monetary economics. Since all of the papers mentioned in the introduction use cashin-advance, henceforth CIA, models, we obviously do not need a search-and-bargaining model to study the effects of inflation and financial intermediation on growth. However, as emphasized by Berentsen et al. (2011) and Shi (1998), the important issue is not one of need, but whether it matters for the results whether one uses microfoundations or a reduced-form approach.

To discuss this issue and to gain further insights into the mechanics of the baseline model, we investigate the role of search, as represented by the parameters $\sigma$ and $\rho$. Furthermore, we construct and calibrate a prototypical CIA-model with a frictionless competitive innovation market, and compare it to the search model.

\subsection{The role of search}

The key for understanding the large effects of inflation on growth and welfare is search. Search is represented by the parameters $\sigma$ and $\rho$, where $\sigma$ reflects the matching frictions in the innovation market, and $\rho$, the time used searching. To highlight the importance of search for our results, we present and discuss the growth and welfare effects for various exogenous values of $\sigma$ or $\rho$.

The effects of the matching probability $\sigma$ In Table 6 , we explore the key effects of the matching friction $\sigma{ }^{27}$ Results for the following values of $\sigma$ are presented: $\sigma=0.052$, which corresponds to the calibrated value of the baseline model; $\sigma=0.026$, which is one half of that amount; $\sigma=0.5$; and $\sigma=1$. The value $\sigma=0.5$ corresponds to the case where all potential innovators are matched; one half of them as buyers and the other half as sellers of innovation time. For $\sigma=1$, the interpretation of the matching process is different. ${ }^{28}$ In this case, all potential innovators that enter the innovation market are randomly matched to one other household, which hires them as innovators. Recall that there is still search time since $\rho>0$, meaning that a potential innovator in a match can work only $1-\rho$ hours.

\footnotetext{
${ }^{27}$ In the following, we only present the calibration results. The derivation of each model and details of the calibration are available as supplementary material. Except for the exogenous choice of $\sigma$, all other elements of these models are equivalent to the baseline model described in Section 4. For each exogenous value of $\sigma$ in Table 6, we remove the target "fraction of loan officers to total employment" (see Table 3 ) and recalibrate the model. Instead of removing this target, we have also removed the target "mean fraction of borrowing of R\&D firms". The results are essentially the same.

${ }^{28}$ We present this case because it is closely related to the natural cash-in-advance model presented below. See the supplementary material, where we derive each model and present more details of the calibration.
} 
Table 6: Effects of matching friction $\sigma$ and search time $\rho$

\begin{tabular}{|l|l|l|l|}
\hline & growth gain in $\mathrm{pp}^{a}$ & welfare gain in $\mathrm{pc}^{b}$ & growth elasticity \\
\hline & & & \\
\hline$\sigma=0.026$ & 0.68645 & 8.02347 & 0.00543 \\
\hline$\sigma=0.052^{d}$ & 0.27701 & 2.26704 & 0.00235 \\
\hline$\sigma=0.5$ & 0.02319 & 0.03003 & 0.00022 \\
\hline$\sigma=1$ & 0.01141 & 0.00762 & 0.00011 \\
\hline & & & \\
\hline$\rho=0$ & 0.25416 & 3.756 & 0.00201 \\
\hline$\rho=0.115^{d}$ & 0.27701 & 2.26704 & 0.00235 \\
\hline$\rho=0.25$ & 0.36654 & 1.77775 & 0.0032 \\
\hline$\rho=0.4$ & 0.91494 & 2.69164 & 0.00781 \\
\hline & & & \\
\hline$\sigma=1$ and $\rho=0$ & 0.0101 & 0.02183 & \\
\hline Natural CIA & 0.0101 & 0.02183 & \\
\hline
\end{tabular}

${ }^{a}$ Growth gain in percentage points from reducing the inflation rate to $0 \%$. ${ }^{b}$ Welfare gain as a percentage of consumption from reducing the inflation rate to $0 \%$. ${ }^{c}$ Elasticity of the growth rate with respect to the net inflation rate. ${ }^{d}$ Corresponds to the baseline calibration. ${ }^{e}$ Effects of inflation in the natural model of cash-in-advance in the innovation market.

The key effects of the matching parameter $\sigma$ are displayed in the first two rows of Table 6. All values in Table 6 are calculated for the average low-inflation country. First, in comparison with the baseline calibration $(\sigma=0.052)$, the growth effects of inflation are much smaller for $\sigma=0.5$ and $\sigma=1$, and strikingly larger for $\sigma=0.026$. For example, for the average low-inflation country, reducing inflation from the historical mean $(5.4 \%)$ to $0 \%$ increases the long-run growth rate by 0.011 percentage points for $\sigma=1$, and by 0.686 percentage points when $\sigma=0.026$. Second, the welfare cost of inflation are much smaller for high values of $\sigma$. For example, for the average low-inflation country, the welfare gain from reducing inflation from the historical mean to zero is $8 \%$ of consumption for $\sigma=0.026$, and only $0.0076 \%$ when $\sigma=1$.

How does inflation affect growth? To understand the mechanism requires us to study the first-order condition for $l$; i.e., equation (25), which, using (2), can be written as follows

$$
\frac{\chi f(i)}{e l R[1+f(i)]}=\theta\left[\rho+\left(r_{\ell}+\sigma\right)(1-\rho)\right]
$$

The left-hand side of (27) is the expected benefit of allocating an additional potential innovator to the innovation market. The right-hand side is the expected cost of doing so, which depends on the borrowing cost $r_{\ell}$. Since, from (27), the measure of innovators $l$ is monotonically decreasing in $r_{\ell}$ and $r_{\ell}$ is increasing in inflation, $l$ is decreasing in 
inflation. Therefore, the growth rate $1+f(i)$ is decreasing in inflation. ${ }^{29}$ The extent to which inflation affects the growth rate depends on $\sigma$, since $\sigma$ affects the elasticity of $l$ with respect to inflation. In Table 6 we present the elasticities of $l$ and $g$ with respect to inflation for various values of $\sigma$. They are decreasing in $\sigma$, meaning that the measure of innovators and hence the real growth rate becomes less sensitive to changes in inflation as $\sigma$ increases. $^{30}$

Why are the effects of inflation on growth sensitive to changes in the matching probability $\sigma$ ? To understand how these elasticities depend on $\sigma$, one needs to understand the costs of holding money. In the baseline model, all money is allocated to the potential innovators. Those that have no access to the innovation market can deposit their money and earn interest $r_{d}$, which partially compensates for the inflation tax. Those that have access to the market earn no interest, rather they borrow additional money at rate $r_{\ell}$. The benefit of holding money (i.e., the opportunity to spend it) only arises with probability $\sigma$, since only with this probability does a potential innovator meet a seller from some other household, who has the needed skills.

A small $\sigma$, thus, means that a large fraction of the money holdings are not spent in a period. That is, while the entire money holdings are subject to the inflation tax, only a small amount of it is spent and generates utility to the household. Consequently, the household reacts very sensitively to a change in the cost of holding money. When inflation increases, the household attempts to reduce its exposure to the inflation tax by reducing the number of members allocated to the innovation sector. With a larger $\sigma$, the cost of holding money remains the same, but now the probability of spending it increases, and so the benefit-cost ratio improves. Consequently, the household reacts less sensitively to changes in the cost of holding money.

A small $\sigma$ captures the empirical evidence on the use of cash for R\&D activities (see our discussion in the introduction): firms with large R\&D activities hold large amounts of cash. Naturally, then, the innovation sector reacts very sensitively to the inflation tax.

The effects of the search time $\rho$ The growth effects of $\rho$ are qualitatively similar to the growth effects of $\sigma$. For example, for the average low-inflation country, reducing inflation from the historical mean $(5.4 \%)$ to $0 \%$ increases the long-run growth rate by 0.27701 percentage points for $\rho=0.115$, and by 0.25416 percentage points for $\rho=0$ (see Table 6 ). For $\rho=0.4$, the growth loss is substantially larger, namely, 0.91494 percentage points. ${ }^{31}$

\footnotetext{
${ }^{29}$ From $(22)$ and $(23), r_{\ell}$ is increasing in the gross growth rate of the money supply $\gamma$; i.e., $\frac{d r_{\ell}}{d \gamma}=\beta^{-1}$. Since $\pi$ and $\gamma$ satisfy $\gamma=(1+\pi) g$ and $g$ is decreasing in $\gamma, \pi$ and $\gamma$ are positively related.

${ }^{30}$ Table 6 presents the elasticities for different values of $\sigma$, where for each value we recalibrate all other parameters using the same targets as for the baseline calibration. Alternatively, one can calculate these elasticities by keeping all other parameters constant. In this case, we can get an explicit expression for the elasticity of $g$ with respect to $\pi$. One can show analytically that this elasticity is decreasing in $\sigma$.

${ }^{31}$ For each exogenous value of $\rho$ in Table 6 , we remove the target "average hours schooling per week" and recalibrate the model. The details of the calibration are available as supplementary material. Except for the exogenous choice of $\rho$, all other elements are equivalent to the baseline model described in Section 4. Notice that we cannot increase $\rho$ above 0.45 , since the calibration would yield a convex innovation function; i.e., $\chi>1$.
} 
Table 6 also shows the elasticity of the growth rate with respect to the net inflation rate. For example, for the average-low inflation country, increasing the inflation rate by $1 \%$; i.e., from $5.4 \%$ to $5.454 \%$, reduces the growth rate by $0.00201 \%$ when $\rho=0$ and by $0.00235 \%$ when $\rho=0.115$. The elasticity of the growth rate with respect to inflation is increasing in $\rho$ : It is almost four times higher for $\rho=0.4$ (0.00781) than for $\rho=0$ (0.00201).

Note that the welfare cost of inflation is lower in the calibrated model with $\rho=0.25$ than in the calibrated model with $\rho=0$. This can be explained as follows. When inflation is reduced to zero, $l$ increases and, thus, the growth rate increases. However, the extent to which the increase in the growth rate improves welfare depends partly on how the loss in leisure time by innovators is valued by the household. A high value of $\rho$ exacerbates the loss in leisure time since innovators must spend more time searching. ${ }^{32}$ As a result, the welfare gain of reducing inflation is not necessarily higher for a higher value of $\rho$.

The case $\rho=0$ and $\sigma=1$ Finally, we report the effects of inflation when there are no search costs, $\rho=0$, and no matching frictions, $\sigma=1$. This case is of interest because it is closely related to the natural model of cash-in-advance presented below. With $\rho=0$ and $\sigma=1$, reducing inflation from $5.4 \%$ to $0 \%$ increases the growth rate by 0.0101 percentage points, and the welfare gain in terms of consumption is $0.02183 \%$. Reducing inflation from $8.8 \%$ to $0 \%$ increases the growth rate by 0.01614 percentage points, and the welfare gain in terms of consumption is $0.04015 \%$. Finally, reducing inflation from $16.9 \%$ increases the growth rate by 0.02985 percentage points, and the welfare gain in terms of consumption is $0.09551 \% .{ }^{33}$

\subsection{A natural model of cash-in-advance in the innovation market}

Consider the following version of the baseline model with no search and a CIA-constraint in the innovation market. The household chooses $l_{s}$ innovators who are employed by other households at the competitive wage $p$. The household also hires $l_{b}$ innovators from other households. The representative household's problem is ${ }^{34}$

$$
V(a, m)=\max _{z}\left\{u[q(h, a)]+\theta\left(1-k-h-l_{s}\right)+\beta V\left(a_{+1}, m_{+1}\right)\right\}
$$

\footnotetext{
${ }^{32}$ This effect is not compensated by the change in the value of $\sigma$, since, given the calibration procedure, the value of $\sigma$ remains unchanged when $\rho$ is modified (see the supplementary material). In contrast, when $\sigma$ is exogenously fixed, the calibrated value of $\rho$ depends on the value of $\sigma$, since $\rho$ adjusts to match the target on average schooling hours.

${ }^{33}$ To obtain these values, we have eliminated the targets "fraction of loan officers to total employment" and "average hours schooling per week." The derivation of the model and its calibration is presented in the supplementary material.

${ }^{34}$ Here, the decision variables of the household are $z=\left\{k, h, l_{b}, l_{s}, b_{\ell}, b_{d}, m_{+1}, a_{+1}\right\}$.
} 
subject to the following constraints:

$$
\begin{aligned}
b_{d} & \leq(1-e) m \\
p l_{b} & \leq e m+b_{\ell} \\
a_{+1} & =a+a f\left(l_{b}\right) \\
m_{+1}-m & =p l_{s}-p l_{b}+r_{d} b_{d}-r_{\ell} b_{\ell}+w k+T .
\end{aligned}
$$

The household enters the period with $m$ units of money. To generate a role for financial intermediation, we assume that he can only use the fraction $e$ to purchase innovation goods. The fraction $1-e$ is illiquid. The household deposits the illiquid funds in the financial sector to earn interest rate $r_{d}$. Financial intermediaries, then, lend it out to other households at interest rate $r_{\ell}$.

The growth and welfare effects of inflation are very small, comparable in magnitude to the ones reported in previous CIA-models mentioned in the Introduction. Furthermore, they are exactly equal to the losses presented above for $\sigma=1$ and $\rho=0$ (see Table 6). This should come as no surprise, as any natural CIA-model with competitive markets ignores search by definition.

\section{Extensions}

In this section, we study two extensions of the baseline model. First, we add an intensive margin by letting the household choose how much time a buyer acquires from the seller in a match. The main effect of the intensive margin is that the model now matches the increase in the interest rate margin that we observe in the data. The growth and welfare effects of inflation are slightly larger than the ones of the baseline model. Second, one might conjecture that our large growth and welfare effects are a result of our assumption that money is only needed in the innovation sector. Here, we show that this is not the case. Rather, if money is also needed for transactions in the goods market, the effects of inflation on growth are larger than in the baseline model.

\subsection{The roles of the intensive and extensive margins}

In this section, we add an intensive margin to the innovation sector by letting the households choose how much innovation time a member buys if he is matched to a seller, denoted as $y$. Furthermore, we assume that the contribution of $y$ units of time to the innovation process is $c(y)$ where $c(y)=c_{0} y^{\alpha}$, with $0<\alpha<1$ and $c_{0}>0$. These assumptions also involve replacing $1-\rho$ by $Y$ in (9), because the quantity $Y$ is chosen by the household's trading partners.

For ease of comparison, we state the representative household's problem: ${ }^{35}$

$$
V(a, m)=\max _{z}\left\{u[q(h, a)]+\theta\{1-k-h-e l(\rho+\sigma Y)\}+\beta V\left(a_{+1}, m_{+1}\right)\right\}
$$

\footnotetext{
${ }^{35}$ Here, the decision variables of the household are $z \equiv\left[q, l, k, h, x, y, b_{\ell}, b_{d}, m_{+1}, a_{+1}\right]$.
} 
subject to (10), (11), (14) and the following constraints:

$$
\begin{aligned}
x \Omega & \geq \theta y \\
a_{+1} & =a+a f[\operatorname{eolc}(y)] .
\end{aligned}
$$

In the above program, the measure of potential innovators that are matched to a buyer of innovation time is $e \sigma l$. Each buyer acquires $y$ units of time where each unit of time contributes to the innovation process $c(y)$ so that the total "effective" time entering the innovation function $f$ is eolc $(y)$. In a match, the buyer continues to make a take-it-orleave-it offer to the seller, which now consists of an amount of money $x$ to be paid by the buyer and a quantity $y$ to be worked by the seller.

Most elements of the derivation are the same as in the baseline model and not repeated here. The new element is the optimal choice of the amount of innovation time to be asked in a match, $y$ :

$$
\sigma \lambda a f^{\prime}(i) c^{\prime}(y)=\left(\sigma+r_{\ell}\right) \theta
$$

This condition equates the marginal benefit of a unit of innovation time to the marginal cost. When the household instructs an innovator to ask the seller to work an additional unit of time, the household will obtain the additional unit with probability $\sigma$, because only with probability $\sigma$ does an innovator have a match in which he is the buyer. The additional unit of innovation time increases the household's productivity in the next period by $a f^{\prime}(i) c^{\prime}(y)$, whose value is $\lambda a f^{\prime}(i) c^{\prime}(y)$ in terms of utility. Thus, the expected marginal benefit of asking for a higher $y$ is $\sigma \lambda a f^{\prime}(i) c^{\prime}(y)$. In order to induce a seller to work an additional unit of time, a buyer needs to offer $\theta / \Omega$ units of money. Carrying this additional amount of money has two costs. First, an innovator needs to borrow the additional amount of money, regardless of whether the innovator will be matched. The unit cost of borrowing is the loan rate $r_{\ell}$. Second, once matched as a buyer (which occurs with probability $\sigma$ ), the innovator needs to pay the additional amount of money to the seller. In terms of utility, the marginal cost of increasing $y$ is $\omega \theta\left(\sigma+r_{\ell}\right) / \Omega$, which becomes the right-hand side of (28) in a symmetric equilibrium where $\Omega=\omega$.

All other elements of the model are equal to the baseline model and, hence, not replicated here. We get the following growth effects of inflation in the presence of the intensive margin. ${ }^{36}$ The growth effects of inflation are of similar magnitude to those presented in the baseline model (almost equal for the high-inflation country and slightly larger for the low-inflation and the medium-inflation countries). Thus, the contribution of the intensive margin to the effects of inflation on growth and welfare is small. In addition, the financial sector size reacts slightly more sensitively to inflation than in the baseline model.

The main difference is that with the intensive margin the net interest-margin is increasing in inflation as it is in the data. ${ }^{37}$ For example, in the data, the interest-rate margin increases by 0.3 percentage points when the rate of inflation increases from $5.4 \%$ to $8.8 \%$, and it increases by 1.9 percentage points when the rate of inflation increases from $8.8 \%$

\footnotetext{
${ }^{36}$ The derivation of this model and the calibration procedure are presented as supplementary material.

${ }^{37}$ Recall that in the baseline model without an intensive margin, the wedge between the deposit and the loan rate is independent of inflation.
} 
to $16.9 \%$ (see Table 1 ). In the model, the equivalent increases are 1.1 and 2.7 percentage points, respectively.

\subsection{Liquidity in the final-goods market}

Let us assume that purchases of final (consumption) goods are subject to a cash-in-advance constraint. In contrast to the baseline model, the household must choose to divide its money between the innovators going to the innovation market and the buyer going to the finalgoods market. ${ }^{38}$ Let $m_{i}$ denote the total amount of money that the household allocates to the innovators. Then, the cash-in-advance constraint in the final-goods market is $m-m_{i} \geq$ $p q$. With this additional constraint, the first-order condition for $q$ is $(q \omega p)^{-1}=\gamma / \beta$, and the first-order condition for $h$ is $\theta=(\eta / h)(\beta / \gamma)$. None of the other first-order conditions is affected. However, the envelope condition for $a$ after some manipulations changes to

$$
R g=\frac{(\beta / \gamma) f \chi}{\theta e l\left[\rho+\left(\sigma+r_{\ell}\right)(1-\rho)\right]}
$$

The time allocation is more sensitive when money is required to buy final goods. Therefore, adding a cash-in-advance constraint in the final-goods market increases the negative growth effect of inflation: In this model, the growth effects are $0.348,0.527$, and 0.872 , respectively for the low, medium and high-inflation countries. ${ }^{39}$ It also substantially increases the negative welfare effect of inflation, since inflation reduces households' consumption not only through its effect on the growth rate, but also through the cash-in-advance constraint: For example, the welfare cost is $3.6 \%$ for the low inflation country and $11 \%$ for the high inflation country. Finally, the financial sector size reacts more sensitively to inflation than in the baseline model: For example, the amount of bank credit for the high-inflation country is $38 \%$ lower than bank credit for the low-inflation country.

\section{Conclusion}

In this paper, we integrated a microfounded model of money and finance into a model of endogenous growth to examine the effects of inflation on growth, welfare and the size of the financial sector. A novel feature of the model is that the market for innovation is decentralized and a medium of exchange is needed for trade to take place. We found that inflation has large effects on growth, welfare and financial sector size. For example, reducing inflation from 10 percent to zero percent increases the annual growth rate by 0.465 percentage points, and the representative household in the economy is willing to give up 4.2 percent of permanent consumption in order to eliminate such inflation. A sizable fraction of the welfare and growth effects of inflation comes from the endogenous

\footnotetext{
${ }^{38} \mathrm{As}$ in the baseline model, we continue to assume that the household needs to send only one buyer and one seller to the consumption-goods market.

${ }^{39}$ To derive these results, we recalibrate the model for the same targets as the baseline model. The derivation of the model and the calibration are available as supplementary material.
} 
response to inflation by the extensive margin of labor input in innovation as opposed to the intensive margin. Our results suggest that the need for liquidity in the innovation sector is an important reason explaining why reducing inflation matters for long-run growth.

An important question is how increasing the efficiency of financial intermediaries affects growth and welfare. In our model, increasing financial productivity to infinity increases the per capita growth rate by 0.01 percentage points for the average low-inflation country and the welfare benefit is approximately 0.3 percent of consumption. These small effects reflect the fact that our financial sector does not capture all the key functions that finance has for R\&D. The way we interpret our model is as follows: Our households represent firms that have already acquired large cash holdings, say, from a successful IPO. What our financial sector does is to help these firms to manage their cash holdings by allowing them to earn interest on "idle" money balances or to borrow additional funds. This is an important function of the financial sector, but certainly not the only crucial one for a successful R\&D sector. To address how financial development affects growth, requires more detailed modeling of how R\&D-intensive firms are financed and how the efficiency of the financial sector affects financing costs. 


\section{References}

[1] Acemoglu, D., P. Aghion, \& F. Zilibotti, 2006. "Distance to frontier, selection and economic growth." Journal of the European Economic Association 4, 37-74.

[2] Acemoglu, D., \& F. Zilibotti, 1997. "Was Prometheus unbound by chance? Risk, diversification and growth." Journal of Political Economy 105(4), 709-751.

[3] Aghion, P., G. Angeletos, A. Banerjee, \& K. Manova, 2010. "Volatility and growth: Credit constraints and the composition of investment." Journal of Monetary Economics 57, 246-265.

[4] Alam, P., \& K. S. Walton, 1995. "Information asymmetry and valuation effects of debt financing." Financial Review 30, 289-311.

[5] Almeida, H., M. Campello, \& M. S. Weisbach, 2004. "The cash flow sensitivity of cash." Journal of Finance 59(4), 1777-1804.

[6] Bailey, M., 1956. "The welfare cost of inflationary finance." Journal of Political Economy 64, 93-110.

[7] Bates, T. W., K. M. Kahle, \& R. M. Stulz, 2009. "Why do U.S. firms hold so much more cash than they used to?" Journal of Finance 64, 1985-2021.

[8] Beck, T., A. Demirgüç-Kunt \& R. Levine, 2001. "The Financial Structure Database.", In Financial Structure and Economic Growth: A Cross-Country Comparison of Banks, Markets, and Development, Demirgüç-Kunt, A. \& R. Levine (eds.), Cambridge, MA: MIT Press: 17-80.

[9] Bencivenga, V. \& B. Smith, 1993. "Some consequences of credit rationing in an endogenous growth model." Journal of Economic Dynamics and Control 17, 97-122.

[10] Berentsen, A., G. Camera, \& C. J. Waller, 2007. "Money, credit and banking." Journal of Economic Theory 135, 171-195.

[11] Berentsen, A., G. Menzio, \& R. Wright, 2011. "Inflation and unemployment in the long run." American Economic Review 101, 371-398.

[12] Berger, A. N., \& G. F. Udell, 1990. "Collateral, loan quality, and bank risk." Journal of Monetary Economics 25, 21-42.

[13] Blazenko, G., 1987. "Managerial preference, asymmetric information, and financial structure." Journal of Finance 42, 839-862.

[14] Boyd, J. \& B. Champ, 2003. "Inflation and financial market performance: What have we learned in the last ten years?" Federal Reserve Bank of Cleveland, Working Paper No. 03-17.

[15] Boyd, J., R. Levine, \& B. Smith, 2001. "The impact of inflation on financial sector performance." Journal of Monetary Economics 47, 221-248.

[16] Brock, P. \& L. Rojas-Suarez, 2000. "Interest spreads in Latin America: Facts, theories and policy recommendations." In Why so high? Understanding interest rate spreads in Latin America, P. Brock \& L. Rojas-Suarez (eds.), Washington: Inter-American Development Bank. 
[17] Brown, J. R. \& B.C. Petersen, 2011. "Cash Holdings and R\&D Smoothing." Journal of Corporate Finance 17(3), 694-709.

[18] Brown, J. R., S. M. Fazzari, \& B. C. Petersen, 2009. "Financing innovation and growth: Cash flow, external equity, and the 1990s R\&D boom." Journal of Finance 64(1), 151-185.

[19] Bruno, M., \& W. Easterly, 1998. "Inflation crises and long-run growth." Journal of Monetary Economics 41, 3-26.

[20] Bureau of Labor Statistics, 2007. "Occupational employment and wages, May 2005." United States Department of Labor, Washington D. C.

[21] Chiu, J., C. Meh \& R. Wright (2011). "Innovation and Growth with Financial, and Other, Frictions." NBER Working Paper No. 17512.

[22] Chari, V. V., L. E. Jones, \& R. E. Manuelli, 1996. "Inflation, Growth, and Financial Intermediation." Federal Reserve Bank of St. Louis Review, May/June.

[23] Craig, B., \& G. Rocheteau, 2005. "Rethinking the welfare cost of inflation." Economic Commentary, Federal Reserve Bank of Cleveland, March 1.

[24] Dotsey, M., \& P. Ireland, 1996. "The welfare cost of inflation in general equilibrium." Journal of Monetary Economics 37, 29-47.

[25] Economic Report of the President. Washington: U.S. Government Printing Office, 2009.

[26] Fisher, S., 1981. "Towards an understanding of the costs of inflation: II." CarnegieRochester Conference Series on Public Policy 15, 5-41.

[27] Friedman, M., 1969. "The optimum quantity of money." In The optimum quantity of money and other essays. Chicago: Aldine,1969.

[28] Friedman, M. \& A. J. Schwartz. Monetary trends in the United States and the United Kingdom, 1867-1975. Chicago: University of Chicago Press, for the National Bureau of Economic Research, 1982.

[29] Gillman, M., \& M. Kejak, 2005. "Contrasting models of the effect of inflation on growth." Journal of Economic Surveys 19(1), 113-136.

[30] Goldsmith, R. W, 1969. Financial structure and development. New Haven, Conn.: Yale University Press, 1969.

[31] Gomme, P., 1993. "Money and growth revisited: Measuring the costs of inflation in an endogenous growth model." Journal of Monetary Economics 32(1), 51-77.

[32] Greenwood, J. \& B. Jovanovic, 1990. "Financial development, growth, and the distribution of income." Journal of Political Economy 98(5), 1076-1107.

[33] Gylfason, T., \& T. T. Herbertsson, 2001. "Does inflation matter for growth?" Japan and the World Economy 13, 405-428. 
[34] Himmelberg, C. P., \& B. C. Petersen, 1994. "R\&D and internal finance: A panel study of small firms in high-tech industries." The Review of Economics and Statistics 76, $38-51$.

[35] Ireland, P. N., 1994. "Money and growth: An alternative approach." American Economic Review 84(1), 47-65.

[36] John, T. A., 1993. "Accounting measures of corporate liquidity, leverage, and costs of financial distress." Financial Management 22(3), 91-100.

[37] Jones, L. E. \& R. E. Manuelli, 1995. "Growth and the effects of inflation." Journal of Economic Dynamics and Control 19, 1405-1428.

[38] Kim, C-S., D. C. Mauer, \& A. E. Sherman, 1998. "The determinants of corporate liquidity: Theory and evidence." Journal of Financial and Quantitative Analysis 33(3), 335-359.

[39] Kim, W., \& M. S. Weisbach, 2008. "Motivations for public equity offers: An international perspective." Journal of Financial Economics 87(2), 281-307.

[40] King, R. G., \& R. Levine, 1993a. "Finance and growth: Schumpeter might be right." Quarterly Journal of Economics 108(3), 717-737.

[41] King, R. G., \& R. Levine, 1993b. "Finance, entrepreneurship and growth. Theory and evidence." Journal of Monetary Economics 32(3), 513-542.

[42] King, R. G., \& S. T. Rebelo, 1993. "Transitional dynamics and economic growth in the neoclassical model." American Economic Review 83, 908-931.

[43] Lach, S., \& M. Schankerman, 1989. "Dynamics of R\&D and investment in the scientific sector." Journal of Political Economy 97, 880-904.

[44] Lagos, R., \& R. Wright, 2005. "A unified framework for monetary theory and policy analysis." Journal of Political Economy 113, 463-484.

[45] Levine, R., 1991. "Stock markets, growth, and tax policy." Journal of Finance 46(4), $1445-1465$.

[46] Levine, R., 2005. "Finance and growth: Theory and evidence". in Handbook of Economic Growth, P. Aghion \& S. N. Durlauf (eds). North-Holland: Elsevier, 2005.

[47] Levine, R., N. Loayza, \& T. Beck, 2000. "Financial intermediation and growth: Causality and causes." Journal of Monetary Economics 46(1), 31-77.

[48] Lucas, R. E. Jr., 1981. "Discussion of Stanley Fisher's "Towards an understanding of the costs of inflation: II." Carnegie-Rochester Conference Series on Public Policy 15, 43-52.

[49] Lucas, R. E. Jr., 1988. "On the mechanics of economic development." Journal of Monetary Economics 22(1), 3-42.

[50] Lucas, R. E. Jr., 2000. "Inflation and welfare." Econometrica 68, 247-274.

[51] McKinnon, R. I., 1973. Money and capital in economic development. Washington DC, Brookings Institution, 1973. 
[52] McLean, R. D., 2011. "Share issuance and cash savings." Journal of Financial Economics 99, 693-715.

[53] McVanel, D. \& N. Perevalov, 2008. "Financial constraints and the cash-holding behaviour of Canadian firms." Bank of Canada, Discussion Paper 2008-16.

[54] Mikkelson, W. H. \& M. M. Partch, 2003. "Do persistent large cash reserves hinder performance?" Journal of Financial and Quantitative Analysis 38(2), 275-294.

[55] Myers, S. C., \& N. S. Majluf, 1984. "Corporate financing and investment decisions when firms have information that investors do not have." Journal of Financial Economics 13(2), 187-221.

[56] Opler, T., L. Pinkowitz, R. Stulz, \& R. Williamson, 1999. "The determinants and implications of corporate cash holdings." Journal of Financial Economics 52, 3-46.

[57] OECD (2008), "OECD Factbook 2008", OECD Factbook Statistics (database).

[58] Ramey, V. A. \& N. Francis, 2009. "A Century of Work and Leisure." American Economic Journal: Macroeconomics 1(2), 189-224.

[59] Rojas Breu, M. (2011). "The welfare effect of access to credit." Economic Inquiry, forthcoming.

[60] Shaw, E. S., 1973. Financial deepening in economic development, Oxford University Press, New York, 1973.

[61] Shi, S., 1997. "A divisible search model of fiat money." Econometrica 65, 75-102.

[62] Shi, S., 1998. "Search for a monetary propagation mechanism." Journal of Economic Theory 81(2), 314-352.

[63] Shleifer, A., \& R. W. Vishny, 1992. "Liquidation values and debt capacity: A market equilibrium approach." Journal of Finance 47(4), 1343-1366.

[64] Silviera, R. \& R. Wright, 2006. "The Venture Capital Cycle." Working paper, University of Pennsylvania.

[65] Silviera, R. \& R. Wright, 2010. "Search and the Market for Ideas." Journal of Economic Theory 145, 1550-1573.

[66] Titman, S. \& R. Wessels, 1988. "The determinants of capital structure choice." Journal of Finance 43, 1-19.

[67] U.S. Census Bureau. Statistical Abstract of the United States. Washington: U.S. Government Printing Office, 2009.

[68] Waller C. J., 2011. "Random Matching and Money in the Neoclassical Growth Model: Some Analytical Results." Macroeconomic Dynamics 15, 293-312.

[69] Zantout, Z. Z., 1997. "A test of the debt-monitoring hypothesis: The case of corporate R\&D expenditures." Financial Review 32(1), 21-48. 